Www.scientiaplena.org.br

\title{
A sustentabilidade das práticas de espeleoturismo no município de Laranjeiras, Sergipe
}

The sustentability of speleoturism pratices in the city of Laranjeiras, Sergipe

\author{
C. R. Donato ${ }^{1 *}$; I. C. B. Silva ${ }^{2}$; M. A. Becker ${ }^{3}$; E. S. Carvalho ${ }^{4}$; H. S. Macedo ${ }^{5}$ \\ ${ }^{1}$ Colégio de Aplicação, Universidade Federal de Sergipe, 49100-000, São Cristóvão-SE, Brasil \\ ${ }^{2}$ Núcleo de Empreendedorismo, Universidade Tiradentes, 49032-971, Aracaju-SE, Brasil \\ ${ }^{3}$ Departamento de Comunicação Social, Universidade Federal de Sergipe, 49100-000, São Cristóvão-SE, Brasil \\ ${ }^{4}$ Departamento de Turismo, Universidade Federal de Sergipe, 49100-000, São Cristóvão-SE, Brasil
}

${ }^{5}$ Programa de Pós-Graduação em Geografia, Universidade Federal de Sergipe, 49100-000, São Cristóvão-SE, Brasil

*christianercrd@yahoo.com.br

(Recebido em 30 de setembro de 2018; aceito em 01 de novembro de 2018)

\begin{abstract}
A relação existente entre o ser humano e as cavernas existe desde as civilizações antigas. As cavidades naturais, suas lendas, mitos e religiões associadas indicam o tipo de relação entre esses ambientes e a população do seu entorno. Dentre as formas de visitação a cavernas, temos o espeleoturismo, uma modalidade do turismo sustentável em que visitantes são guiados por profissionais qualificados para vivenciarem experiências dentro do ambiente cavernícola e no seu entorno. Para analisar os graus de sustentabilidade do espeleoturismo em cavernas do município de Laranjeiras/Sergipe, a metodologia foi organizada de acordo com os objetivos específicos, utilizando para isso, o método de avaliação potencial de espeleoturismo, em que suas deliberações foram adaptadas à realidade do município estudado e o uso de um questionário, para reconhecer a percepção socioambiental dos moradores de Laranjeiras sobre as cavernas e seu entorno. Os resultados apontam que nenhuma das cavernas pesquisadas obteve potencial absoluto, intenso ou alto para espeleoturismo. A Gruta da Matriana, a Gruta Raposinha e a Gruta da Pedra Furada possuem 50\% de potencial, classificando-as como de média potencialidade. A Gruta Aventureiros, a Gruta da Pseudomatriana e a Gruta dos Orixás possuem 33,33\% de potencial, classificando-as, junto com a Gruta da Raposa e a Gruta do Tramandaí com 22,22\% de potencial, em potencialidade moderada. A Gruta da Janela foi a única considerada inapta ao turismo, pois apresenta risco de contaminação patológica por Loxoceles sp. (aranhamarrom) e Lutzomyia sp. (mosquito-palha).
\end{abstract}

Palavras-chave: Sustentabilidade, Cavernas, Espeleoturismo.

The relationship between human beings and the caves existed since ancient civilizations. The natural cavities, legends, myths and religions associated indicate the type of relationship between these environments and the people of your surroundings. Among the forms of visitation to caves, we have speleotourism, a sustainable tourism sustainable tourism where visitors are led by trained staff experiencing experiences within the cave environment and its surroundings. To analyze the degree of sustainability of speleotourism in the city of Laranjeiras/Sergipe caves, the methodology was organized according to the objectives through the potential for this evaluation method speleotourism, in which its deliberations were adapted to the reality the city studied and the use of a questionnaire to recognize the environmental awareness of the residents of Laranjeiras about the caves and its surroundings. The results show that none of the surveyed caves got absolute potential, intense or high for speleotourism. The Caverna da Matriana, the Gruta da Raposinha and the Gruta da Pedra Furada have 50\% potential, classifying them as average capability. The Caverna dos Aventureiros, the GRuta da Pseudomatriana and the Caverna dos Orixás have $33.33 \%$ of potential, classifying them, along with the Gruta da Raposa and the Gruta do Tramandaí with $22.22 \%$ of potential, moderate potential. The Gruta da Janela was the only deemed unfit to tourism, it presents risk of pathological contamination Loxoceles sp. (brown spider) and Lutzomyia sp. (sandfly).

Keywords: Sustainability, Caves, Speleotourism.

\section{INTRODUÇÃO}

A relação existente entre o ser humano e as cavernas existe desde as civilizações antigas. Referências a essa ligação são feitas primeiramente na Era Pré-Histórica, em seguida, na Grécia 
Antiga, na Roma antiga, nas civilizações pré-colombianas, entre outros [2]. Logo, a afinidade existente entre homens e cavernas é tão antiga quanto sua própria história. Situação expressa em forma de sítios arqueológicos com datações bem diferentes espalhados por todo o mundo.

As cavidades naturais, suas lendas, mitos e religiões associadas indicam o tipo de relação entre esses ambientes e a população do seu entorno. Atualmente, cavernas são utilizadas como santuários, a exemplo das existentes em serras no alto Rio Negro no Amazonas para os ianomâmis [3]. Em algumas ocorrem peregrinações regulares, a exemplo da Gruta de São Francisco em Quixadá [4], da Gruta da Anunciação em Nazaré [5] e do Santuário do Bom Jesus da Lapa, localizado em um município homônimo [2].

As cavernas têm sido utilizadas como: abrigo humano [6]; fontes de água para abastecimento de fazendas e cidades; mineração [7]; e para a prática do espeleoturismo. São o espeleoturismo e a mineração, todavia, as formas mais usuais de utilização de cavernas.

Esses ambientes se apresentam como lugares propícios para o desenvolvimento do turismo, uma vez que comportam belezas que fascinam o homem, além de constituir uma forma de turismo de alto potencial educativo [8], revelando a estreita relação entre o meio ambiente e o turismo.

Do turismo sustentável, o espeleoturismo é uma modalidade em que visitantes são guiados por profissionais qualificados para vivenciarem experiências dentro do ambiente cavernícola e no seu entorno. O espeleoturismo se apresenta como uma modalidade que visa a conservação das cavernas, o desenvolvimento econômico local, a satisfação e conscientização dos turistas [9], minimizando, dessa forma, os impactos negativos causados pela visitação.

Essa modalidade turística tem relatos de início no século XIX como as grutas de Fingal na GrãBretanha, mas estima-se que tenha iniciado ainda em 1213 à Caverna de Postojna. Atualmente, cavernas européias recebem mais de duzentos mil visitantes por ano, como a caverna Han-SurLesse na Bélgica. Mas é a Caverna de Postojna, na Eslovênia, a cavidade natural mais visitada na Europa com uma média de quinhentos mil visitantes anuais, e que em 1962 atingiu a marca de cinco milhões de visitantes em um único ano [10]. No Brasil existem mais de cinquenta cavernas com turismo regular, incluindo religioso, como a Caverna do Diabo em São Paulo, Maquiné em Minas Gerais e Lapa Doce na Bahia.

Em Sergipe, as cavernas possuem procura no mercado de turismo, podendo-se situar o início do reconhecimento desses ambientes em território sergipano, em 1888, com as indicações de cavidades naturais feitas por Branner (1888) [11] nos municípios de Divina Pastora (i.e., caverna do Urubu) e Laranjeiras (i.e., caverna da Pedra Furada). Como registros posteriores, podem ser citados a publicação do IBGE [12] e as explorações de José Augusto Garcez na década de 1970 [13]. Foi a partir da década de 2000 que aumentou a presença de registros preliminares [14], paleontológicos [15-17], biológicos e ecológicos [18-26], relativo à conservação e dinâmica ambiental [27-33] das cavidades subterrâneas sergipanas. Entretanto, mesmo com o aumento do número de cavernas registradas e estudadas no Estado, pouco se vem pesquisando quanto ao seu uso voltado ao espeleoturismo.

Dentre as cavernas conhecidas, registradas, com estudos prévios e que possuem algum tipo de visitação, algumas que estão situadas no município de Laranjeiras, Estado de Sergipe, foram nosso foco de estudo. Esse município e suas cavernas foram escolhidos por: estar localizado a $18 \mathrm{~km}$ de Aracaju; ser o município com maior número de cavernas conhecidas e registradas do Estado; as cavernas possuem beleza cênica e uma riqueza histórico-cultural que se entrelaça com a história do município e dos moradores locais [34]; há uma incipiente ocorrência de visitação para conhecer esses ambientes; e nenhuma das cavernas possui plano de manejo.

Nesse cenário, o objetivo geral da pesquisa foi analisar o potencial de sustentabilidade do espeleoturismo em cavernas do município de Laranjeiras, Sergipe. Como objetivos específicos pretende-se identificar quais as cavernas de Laranjeiras possuem potencialidade espeleoturística; reconhecer a percepção socioambiental dos moradores de Laranjeiras sobre as cavernas e seu entorno; identificar ações que viabilizem desenvolver o espeleoturismo de forma sustentável nas cavernas do município de Laranjeiras. 


\section{MATERIAL E MÉTODOS}

\subsection{Delimitação e caracterização da área de estudo}

A pesquisa foi realizada no Município de Laranjeiras, Sergipe (Figura 1), o qual possui 163,60 $\mathrm{km}^{2}$, localizado na mesorregião Leste Sergipano, microrregião do Baixo Cotinguiba, na divisão climática Litoral Úmido [35]. Limita-se ao norte com os municípios de Riachuelo e Maruim, ao sul com Nossa Senhora do Socorro, a leste com Santo Amaro das Brotas e a oeste com Itaporanga D’Ajuda e Areia Branca [36].

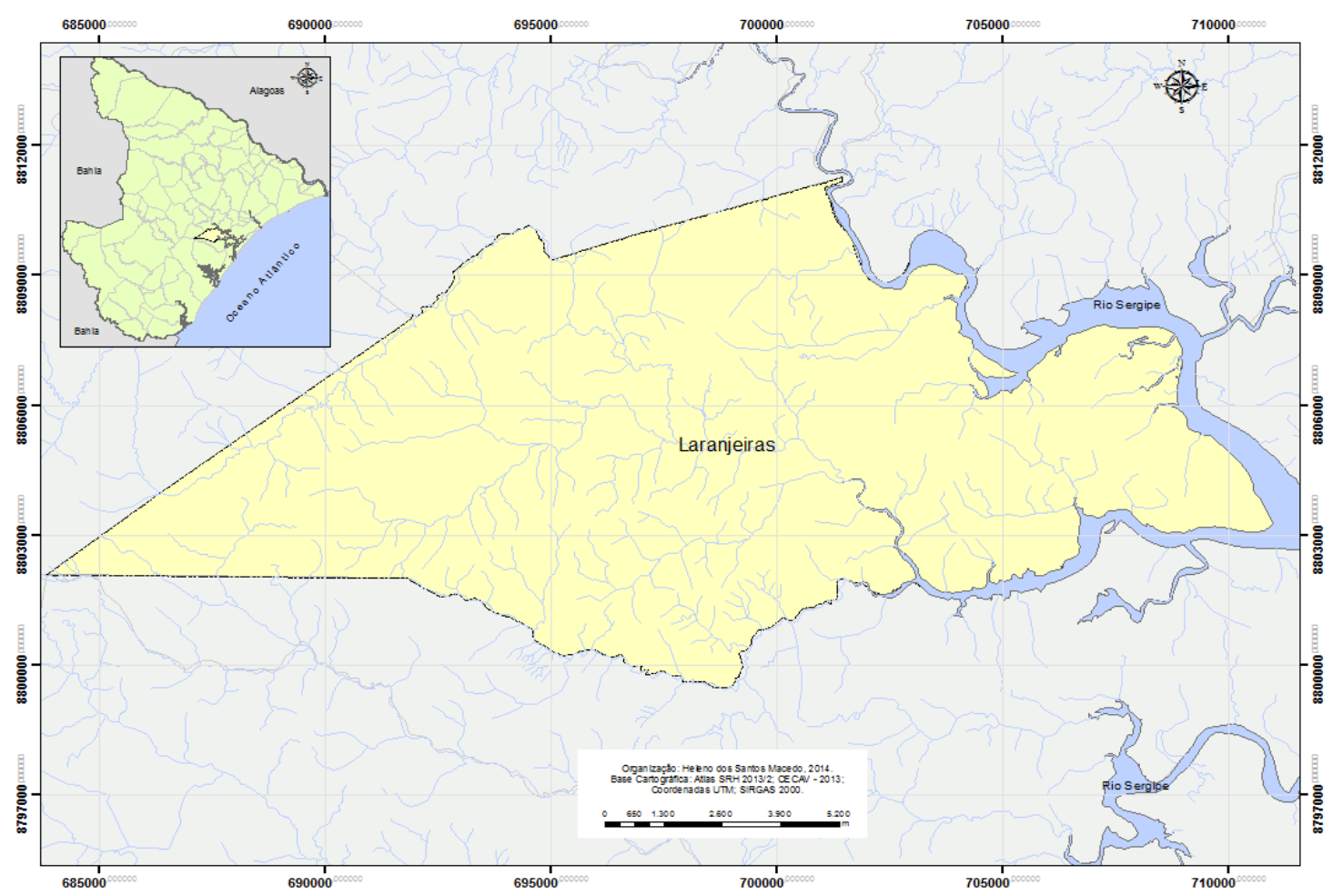

Figura 1: Mapa de localização do município de Laranjeiras, em Sergipe, nordeste do Brasil.

É considerado o município berço da cultura, educação, política e economia e, não se tornou capital de Sergipe devido apenas a uma manobra política do Barão de Maruim, quem transferiu a sede de São Cristóvão para Aracaju. Situa-se a 18 km de Aracaju e possui marcas da época colonial, com ruas, casarios e igrejas que fazem parte do patrimônio histórico de Sergipe, já que possui características da época, as quais estão em processo de restauração [37]. A existência desse acervo cultural e histórico fez com que, em março de 1971, através do Decreto $\mathrm{n}^{\circ} 2.048$, do Governo Estadual, a cidade de Laranjeiras fosse decretada Monumento Histórico. Em 1996, o Instituto do Patrimônio Histórico e Artístico Nacional (IPHAN) decretou o tombamento definitivo do Conjunto Arquitetônico [38, 39].

Quanto às suas características climáticas, possui temperatura média de $25,5^{\circ} \mathrm{C}$, o índice pluviométrico médio é de $1200 \mathrm{~mm}$ por ano, com chuvas concentradas entre os meses de março e agosto. Está localizado na Bacia Hidrográfica do Rio Sergipe, banhado pelo Rio Cotinguiba e Madre-deus. A maior parte do solo é coberta por áreas cultivadas e pastagem, mas existe manguezal próximo aos rios e poucos espaços de mata secundária e Mata Atlântica [40].

As cavernas analisadas quanto ao potencial espeloturístico foram: Gruta Aventureiros

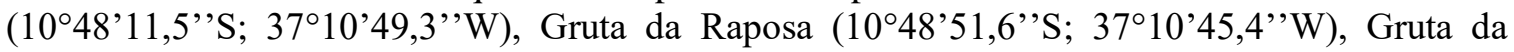
Matriana $\left(10^{\circ} 48^{\prime} 04,0^{\prime}\right.$ 'S; $\left.37^{\circ} 10^{\prime} 46,8^{\prime \prime} \mathrm{W}\right)$ e Gruta da Pseudomatriana (1047'51,6'S; $\left.37^{\circ} 10^{\prime} 55,7^{\prime \prime} \mathrm{W}\right)$, localizadas no Povoado Comandaroba; e Gruta da Janela (1049'22,2' 'S; $\left.37^{\circ} 10^{\prime} 28^{\prime \prime} \mathrm{W}\right)$, Gruta do Tramandaí $\left(10^{\circ} 49^{\prime} 03,5^{\prime \prime} \mathrm{S} ; 37^{\circ} 10^{\prime} 12,5^{\prime \prime} \mathrm{W}\right)$, Gruta dos Orixás

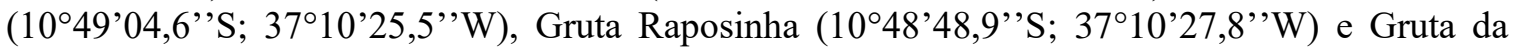
Pedra Furada (1049'14,7'’S; 37¹0’40,2'’W), localizadas no Povoado Machado. 


\subsection{Metodologia}

Para analisar o potencial de sustentabilidade do espeleoturismo em cavernas do município de Laranjeiras/Sergipe a metodologia foi organizada de acordo com os objetivos específicos. Uma vez que, com os objetivos específicos alcançados, o objetivo geral seria atingido ao final.

Para identificar quais cavernas de Laranjeiras possuem potencialidade espeleoturísticas foi utilizado o método de avaliação potencial de espeleoturismo de Lobo (2007) [1], modificado, com suas deliberações adaptadas à realidade do município estudado. Para essa identificação os atributos apresentados pelas cavernas foram classificados quanto à fragilidade, potencialidade geral e potencialidade contemplativa. As variáveis que limitam a visitação são as apresentadas como fragilidades e as variáveis que motivam a visitação são as de potencialidade geral e contemplativa. Cada uma dessas classificações teve suas escalas de valores fixadas para preenchimento das planilhas e graduação de suas situações (Quadro 1). A fragilidade $(\mathrm{F})$ pode ser baixa $(\mathrm{B})$, média (M), alta (A) ou absoluta (Ab) e o potencial geral (PG) e o potencial contemplativo (PC) podem ser baixo (B), médio (M) ou alto (A).

Quadro 1: Classificação e escala de valores dos indicadores para indicação de potencial turístico em cavernas (adaptado de Lobo, 2007[1]).

\begin{tabular}{|c|c|c|c|c|}
\hline \multicolumn{5}{|c|}{ Grau de Fragilidade (máximo 16 pontos) } \\
\hline Baixo (3) & \multicolumn{2}{|c|}{ Médio (2) } & Alto (1) & Absoluto (0) \\
\hline $\begin{array}{l}\text { Até } 5 \text { fragilidades } \\
\text { detectadas }\end{array}$ & \multicolumn{2}{|c|}{$\begin{array}{l}\text { De } 6 \text { a } 10 \\
\text { fragilidades } \\
\text { detectadas }\end{array}$} & $\begin{array}{l}11 \text { ou mais } \\
\text { fragilidades } \\
\text { detectadas }\end{array}$ & $\begin{array}{l}\text { Fragilidade } \\
\text { incompatível para } \\
\text { o turismo }\end{array}$ \\
\hline \multicolumn{5}{|c|}{ Classificação da potencialidade e escala de valores } \\
\hline \multicolumn{5}{|c|}{ Grau de Potencialidade Geral (máximo 10 pontos) } \\
\hline \multicolumn{2}{|l|}{ Baixo (1) } & \multicolumn{2}{|c|}{ Médio (2) } & Alto (3) \\
\hline \multicolumn{2}{|c|}{$\begin{array}{l}\text { De } 1 \text { a } 3 \text { potencialidades } \\
\text { detectadas }\end{array}$} & $\begin{array}{l}\text { Entre } 4 \\
\text { potencia } \\
\text { detectac }\end{array}$ & & $\begin{array}{l}7 \text { ou mais potencialidades } \\
\text { detectadas }\end{array}$ \\
\hline \multicolumn{5}{|c|}{ Grau de Potencialidade Contemplativa (máximo de 9 pontos) } \\
\hline \multicolumn{2}{|l|}{ Baixo (1) } & \multicolumn{2}{|c|}{ Médio (2) } & Alto (3) \\
\hline \multicolumn{2}{|c|}{$\begin{array}{l}\text { De } 1 \text { a } 3 \text { potencialidades } \\
\text { detectadas }\end{array}$} & $\begin{array}{l}\text { Entre } 4 \\
\text { potencia } \\
\text { detectac }\end{array}$ & & $\begin{array}{l}7 \text { ou mais potencialidades } \\
\text { detectadas }\end{array}$ \\
\hline
\end{tabular}

Após construir o critério de como valorar os indicadores presentes nas cavernas, foi organizada uma matriz de correlação (Quadro 2) a ser preenchida em cada cavidade natural observada. Nela há separação entre atributos, indicadores de cada atributo, pontuação para cada indicador, pontuação geral de cada atributo, classificação de cada pontuação por atributo e classificação geral da caverna quanto ao potencial espeleoturístico. A matriz de correlação pode servir para comparar a mesma caverna em momentos diferentes e para comparar cavernas distintas em um mesmo momento ou ao longo do tempo.

Após preencher a matriz de correlação, foram obtidos os valores para a classificação das cavernas, de acordo com a análise integrada (Quadro 2). A avaliação foi obtida pela multiplicação do valor da fragilidade $(3,2,1$ ou 0$)$ pela soma do potencial geral $(3,2$ ou 1) com o potencial contemplativo $(3,2$ ou 1$)$, tudo isso dividido pelo total de pontos possíveis (18). O resultado é multiplicado por 1000 para obter o valor em porcentagem. Essa análise divide os resultados por 
porcentagem obtida e cada intervalo de porcentagem indica uma classificação para as cavernas avaliadas.

Quadro 2: Análise final integrada do potencial espeloturístico (PE) (adaptado de Lobo, 2007[1]).

\begin{tabular}{|c|c|}
\hline Resultado final PE & Classificação das cavernas \\
\hline $87-100 \%$ & Absoluta \\
\hline $69-86 \%$ & Intensa \\
\hline $54-68 \%$ & Alta \\
\hline $36-53 \%$ & Média \\
\hline $19-35 \%$ & Moderada \\
\hline $1-18 \%$ & Baixa \\
\hline $0 \%$ & Caverna inapta ao turismo \\
\hline & \\
\hline & $F^{*}(\mathbf{P G}+\mathbf{P C})$ \\
\hline
\end{tabular}

Considerando:

$\mathrm{F}=$ fragilidades $; \mathrm{PG}=$ potencial geral $; \mathrm{PC}=$ potencial de contemplação; $\mathrm{TPP}=$ Total de pontos possíveis (18 pontos para o $\mathrm{PE}$ ).

Para reconhecer a percepção socioambiental dos moradores de Laranjeiras sobre as cavernas e seu entorno, foi elaborado, primeiramente, um questionário com dezessete perguntas. $\mathrm{O}$ questionário elaborado foi aplicado no Povoado Machado com trinta representantes de famílias moradoras, após preenchimento do "Termo de consentimento livre e esclarecido". As entrevistadoras faziam as perguntas oralmente e anotavam no questionário as respostas dos entrevistados. Essas entrevistas foram realizadas no mês de fevereiro de $2013 \mathrm{com}$ a amostragem aleatória das 120 famílias presentes no povoado.

As perguntas utilizadas no questionário foram: 1) Nome Completo; 2) Idade; 3) Profissão; 4) Escolaridade; 5) Local onde nasceu; 6) Onde reside atualmente; 7) Você conhece as cavernas em Laranjeiras? 8) Você gosta das cavernas de Laranjeiras? 9) Você gostaria de conhecer melhor as cavernas de Laranjeiras? 10) Você acha que outras pessoas gostariam de conhecê-las? 11) Você acha que a cidade valoriza as cavernas? 12) Você já ouviu falar do turismo de cavernas? 13) Você acha que esse tipo de turismo interessaria a Laranjeiras? 14) Você acha que a cidade está preparada para receber turistas interessados em conhecer as cavernas de Laranjeiras? 15) Você acha que esse tipo de turismo tornaria Laranjeiras conhecida? 16) Você acha que esse tipo de turismo contribuiria com a economia da cidade? 17) Esse tipo de turismo poderia trazer benefícios à população?

Para identificar que ações devem ser colocadas em prática, para viabilizar o desenvolvimento do espeleoturismo de forma sustentável nas cavernas do município de Laranjeiras, foi realizada pesquisa para levantar a produção para fins de planejamento do turismo nesse município. $\mathrm{O}$ documento encontrado e analisado foi o Inventário da Oferta Turística, produzido em 2012, para subsidiar a elaboração de projetos de desenvolvimento local.

Nesse mesmo ano, foi realizado o Curso Básico de Monitores Ambientais, com carga horária de 160 horas, formando moradores locais para atuarem na condução de visitantes em áreas naturais, além de estar aptos a contribuir para o monitoramento dos impactos socioambientais nas áreas de visitação, de acordo com proposta do Projeto intitulado "Identificação e estruturação de potencialidades turísticas associadas às cavernas do município de Laranjeiras/SE", executado pelo Centro da Terra: Grupo Espeleológico de Sergipe. 


\section{RESULTADOS E DISCUSSÃO}

\subsection{Potencial espeleoturístico das cavernas}

Utilizando-se a metodologia de Lobo (2007) [1], modificada, observaram-se as nove cavernas com estudos anteriores de fragilidade ambiental e obtiveram-se resultados quanto: a) a identificação dos indicadores de fragilidade e potencialidade do espeleoturismo. Os indicadores escolhidos foram organizados em uma matriz de correlação, como explicitado na metodologia (Quadro 3); b) ao enquadramento das cavernas em categorias de potencialidade espeleoturística; c) a indicação das cavernas que podem vir a ser utilizadas para o espeleoturismo.

Quadro 3: Matriz de correlação para identificar potencial espeleoturístico nas cavernas observadas, exemplo com Gruta da Pedra Furada em Laranjeira, Sergipe.

\begin{tabular}{|c|c|c|c|c|c|c|}
\hline \multicolumn{7}{|c|}{ Matriz de correlação } \\
\hline $\begin{array}{r}\text { Caverna } \\
\text { estudada }\end{array}$ & $\begin{array}{c}\text { Atributos } \\
\text { gerais }\end{array}$ & Indicadores & $\begin{array}{l}\text { Valor } \\
\text { obtido por } \\
\text { indicador }\end{array}$ & $\begin{array}{l}\text { Valor } \\
\text { geral por } \\
\text { categoria }\end{array}$ & \begin{tabular}{|c|} 
Classificação \\
F (PMAA) e \\
PG, PC \\
(PMA)
\end{tabular} & $\begin{array}{l}\text { Classificação } \\
\text { final (por cor) }\end{array}$ \\
\hline \multirow{12}{*}{ 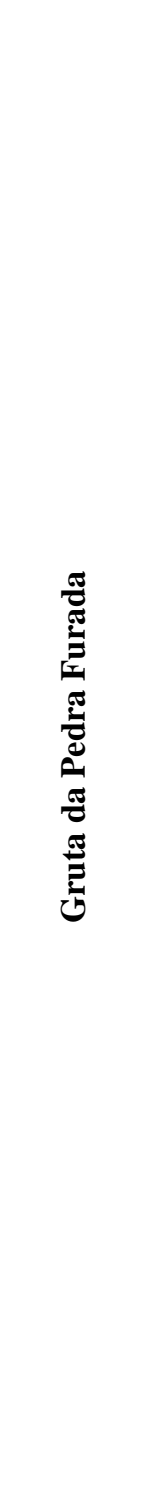 } & \multirow{12}{*}{ 焉 } & $\begin{array}{l}\text { Presença de vestígio } \\
\text { arqueológico }\end{array}$ & & \multirow{12}{*}{3} & \multirow{12}{*}{$3(\mathrm{P})$} & \multirow{12}{*}{50 (Média) } \\
\hline & & $\begin{array}{l}\text { Presença de vestígio } \\
\text { paleontológico }\end{array}$ & & & & \\
\hline & & $\begin{array}{l}\text { Presença de espécie } \\
\text { endêmica }\end{array}$ & & & & \\
\hline & & $\begin{array}{l}\text { Presença de espécie } \\
\text { troglomórfica }\end{array}$ & & & & \\
\hline & & $\begin{array}{l}\text { Risco de contaminação } \\
\text { patológica }\end{array}$ & & & & \\
\hline & & $\begin{array}{l}\text { Presença de odor } \\
\text { desagradável }\end{array}$ & & & & \\
\hline & & $\begin{array}{l}\text { Presença de indícios de } \\
\text { instabilidade geológica }\end{array}$ & & & & \\
\hline & & $\begin{array}{lr}\text { Presença de } & \text { cursos } \\
\text { d'água } & \text { com } \\
\text { possibilidades } & \text { de } \\
\text { enchentes repentinas }\end{array}$ & & & & \\
\hline & & $\begin{array}{lr}\text { Presença } & \text { de } \\
\text { espeleotemas sujeitos a } \\
\text { danos físicos pelo } \\
\text { contato }\end{array}$ & & & & \\
\hline & & $\begin{array}{ll}\text { Presença } & \text { de } \\
\text { espeleotemas raros } & \end{array}$ & & & & \\
\hline & & $\begin{array}{l}\text { Presença de } \\
\text { espeleotemas compostos } \\
\text { por minerais raros }\end{array}$ & & & & \\
\hline & & $\begin{array}{l}\text { Presença de áreas com } \\
\text { baixa circulação de } \\
\text { energia }\end{array}$ & & & & \\
\hline
\end{tabular}




\begin{tabular}{|c|c|c|c|c|}
\hline & $\begin{array}{l}\text { Presença de ambientes } \\
\text { comprometidos por } \\
\text { degradação/depredação }\end{array}$ & 1 & & \\
\hline & $\begin{array}{lll}\text { Existência de objetos de } \\
\text { estudo } & \text { de alguma } \\
\text { pesquisa } & \text { científica na } \\
\text { caverna } & & \end{array}$ & 1 & & \\
\hline & $\begin{array}{l}\text { Localização da caverna } \\
\text { fora de área legalmente } \\
\text { protegida }\end{array}$ & 1 & & \\
\hline & $\begin{array}{l}\text { Localização da caverna } \\
\text { em área autorizada para } \\
\text { lavra minerária ou com } \\
\text { mineração a no mínimo } \\
\text { 300m de distância }\end{array}$ & & & \\
\hline \multirow{10}{*}{ 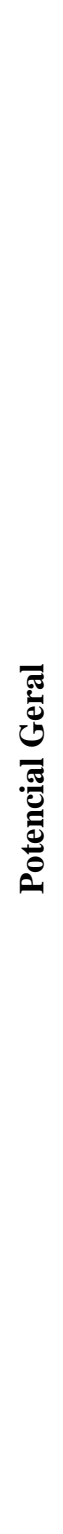 } & $\begin{array}{l}\text { Presença de cursos ou } \\
\text { corpos d'água no interior } \\
\text { da caverna }\end{array}$ & & \multirow{10}{*}{5} & \multirow{10}{*}{$2(\mathrm{M})$} \\
\hline & $\begin{array}{l}\text { Presença de temperatura } \\
\text { ideal da água para banho } \\
\left(19^{\circ} \text { a } 26^{\circ} \mathrm{C}\right)\end{array}$ & & & \\
\hline & $\begin{array}{l}\text { Presença de água } \\
\text { transparente }\end{array}$ & & & \\
\hline & $\begin{array}{l}\text { Cavidade com mais de } \\
\text { um acesso próximo }\end{array}$ & 1 & & \\
\hline & Presença de clarabóia & & & \\
\hline & $\begin{array}{l}\text { Presença de temperatura } \\
\text { ambiente interna entre } \\
18^{\circ} \text { e } 22^{\circ} \mathrm{C}\end{array}$ & & & \\
\hline & $\begin{array}{l}\text { Presença de boas } \\
\text { condições internas de } \\
\text { resgate }\end{array}$ & 1 & & \\
\hline & $\begin{array}{|lcr|}\begin{array}{l}\text { Presença } \\
\text { condições }\end{array} & \text { externas } & \text { boas } \\
\text { resgate } & & \text { de } \\
\end{array}$ & 1 & & \\
\hline & 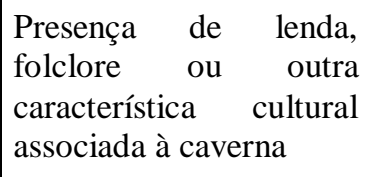 & 1 & & \\
\hline & $\begin{array}{l}\text { Presença de condutas de } \\
\text { acesso suficientemente } \\
\text { altos e largos para } \\
\text { passagem de pessoas } \\
\text { (largura mínima } 1,50 \mathrm{~m} \text { e } \\
\text { altura mínima } 1,90 \mathrm{~m}\end{array}$ & 1 & & \\
\hline
\end{tabular}




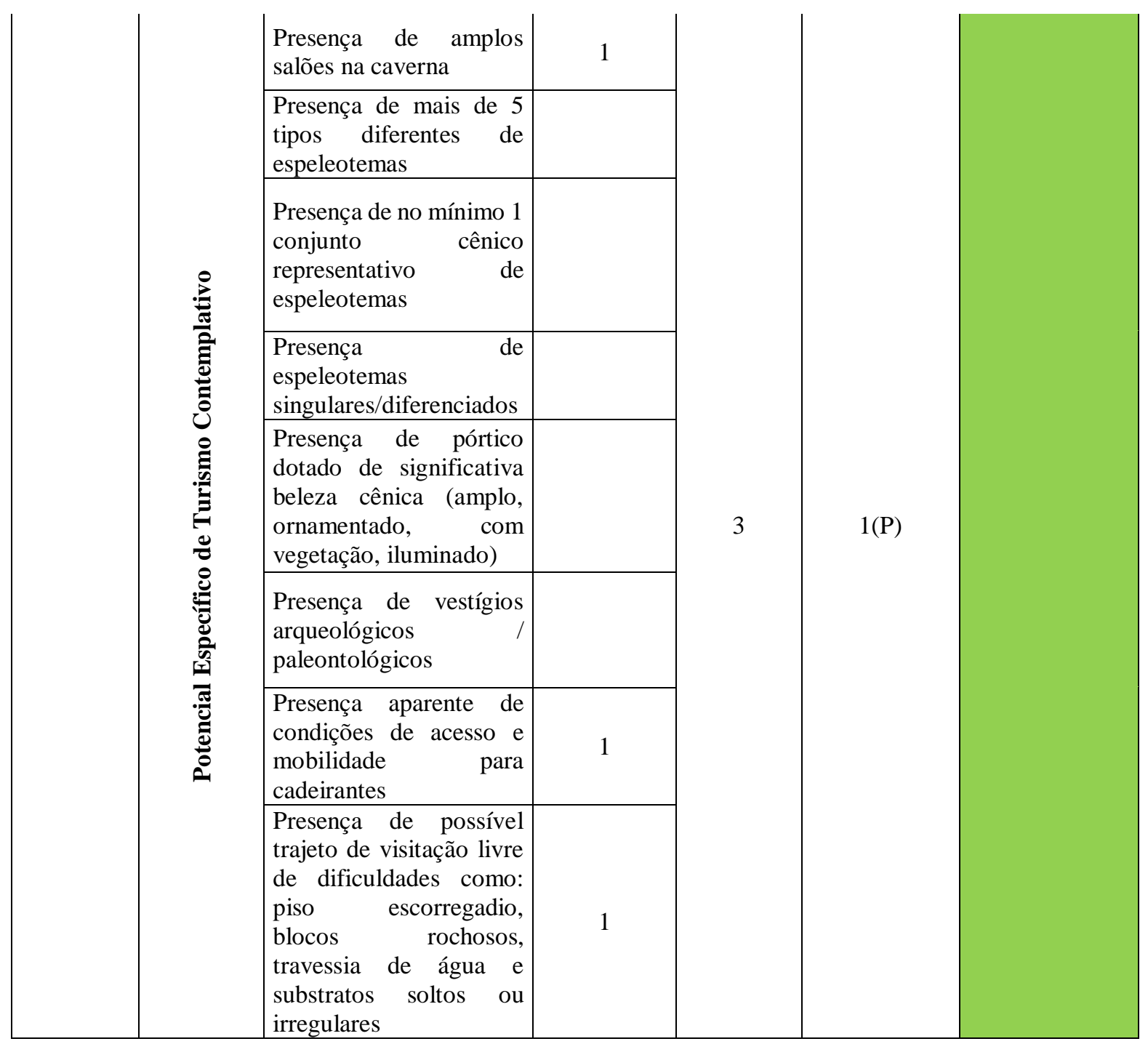

Com o preenchimento da matriz de correlação e análise final integrada dos valores obtidos, é possível verificar a que categoria de potencialidade espeleoturística cada caverna pertence. Nenhuma das cavernas pesquisadas obteve potencial absoluto, intenso ou alto para espeleoturismo. A Gruta da Matriana, a Gruta Raposinha e a Gruta da Pedra Furada possuem 50\% de potencial, classificando-as como de média potencialidade. A Gruta Aventureiros, a Gruta da Pseudomatriana e a Gruta dos Orixás possuem 33,33\% de potencial, classificando-as, junto com a Gruta da Raposa e a Gruta do Tramandaí com $22,22 \%$ de potencial, em potencialidade moderada.

A Gruta da Janela foi a única considerada inapta ao turismo, pois apresenta risco de contaminação patológica por Loxoceles sp. (aranha-marrom) e Lutzomyia sp. (mosquito-palha). A aranha-marrom é uma das aranhas de veneno mais intenso no Brasil e o mosquito-palha pode ser responsável pela propagação da Leishmaniose [32].

Dentre as cavernas indicadas com potencial médio, classificação mais alta obtida entre as cavidades naturais subterrâneas investigadas, indicam-se apenas as presentes no Povoado Machado (Gruta Raposinha e Gruta da Pedra Furada) para visitação turística. A Gruta da Matriana possui importância histórica, mas hoje está ilhada em meio ao canavial e está constituída por três paredões que se organizam como ângulos de um triângulo com o centro aberto, sem teto e apresentando vegetação secundária. A Gruta Raposinha está localizada em propriedade privada e possui pequenas dimensões, mas seria exemplo de uma caverna com degradação irreversível (teto com estalactites quebradas) e seu formato mais fechado poderia ser um contraponto à caverna maior e mais aberta (Gruta da Pedra Furada). Essa última possui lendas e histórias associadas e é a caverna mais conhecida do Estado de Sergipe. 
Quanto aos impactos causados pela moradia e visitação, como medida mitigadora, recomendase a total eliminação do lixo e um trabalho de recuperação da vegetação na área de entorno, bem como a elaboração de um programa de educação ambiental e da institucionalização do planejamento do espeleoturismo e consequente manejo na região [41].

A atividade turística se apresenta com um grande potencial econômico e capacidade de gerar renda e emprego nas localidades onde é desenvolvida e, o espeleoturismo tem sido visto como uma alternativa viável, utilizando-se dos recursos naturais. Entretanto, é necessário que essas atividades sejam bem conduzidas, devido à grande fragilidade do sistema cavernícola. A determinação da capacidade de suporte, delimitação da área de visita, a capacitação de guias locais, a conscientização de todos os envolvidos, a elaboração de planos de manejo espeleológicos e projetos de educação ambiental, tornam-se essenciais para garantir o uso sustentável das cavernas [42].

\subsection{Percepção socioambiental da comunidade do entorno quanto à viabilidade turística sustentável das cavernas}

As entrevistas foram realizadas no Povoado Machado, localidade onde as cavernas indicadas para uso espeleoturístico estão situadas, com o intuito de verificar o que a população do entorno achava quanto ao benefício e viabilidade do turismo para elas e para os ambientes cavernícolas.

Quando perguntados "se conheciam as cavernas em Laranjeiras", 63,3\% dos entrevistados conhecem apenas a Pedra Furada, 10\% nunca ouviram falar e somente dois conhecem todas as cavernas registradas, sendo estes os que possuem experiência com o turismo local. No questionamento sobre "se eles gostavam das cavernas de Laranjeiras", a maioria dos entrevistados respondeu que gostavam pouco das cavernas que conheciam, perfazendo um total de $36,6 \%$; entre aqueles que gostam das cavernas medianamente e muito o resultado foi igual a 26,7\%. Entretanto, metade dos entrevistados afirma que gostariam muito de "conhecer melhor as cavernas de Laranjeiras"; enquanto apenas 6,7\% afirmam não ter nenhum interesse de conhecê-las.

Questionados se "outras pessoas gostariam de conhecer as cavernas de Laranjeiras", mais da metade dos entrevistados $(56,7 \%)$ acreditam que outras pessoas teriam interesse de conhecer as cavernas de Laranjeiras e somente 3,3\% afirmaram que outras pessoas não teriam nenhum interesse. Apesar dos entrevistados responderem que eles e outras pessoas podem ter muito interesse de conhecer melhor as cavernas de Laranjeiras, quase a metade deles (46,6\%) também confirmam que "a cidade (população e poder público) não valoriza" nada e $40 \%$ valorizam pouco as suas cavernas.

Mesmo havendo visitação desordenada e turismo esporádico nas cavernas de Laranjeiras, 43,3\% dos entrevistados poucos ouviram falar "do turismo em cavernas (espeleoturismo)" e 26,7\% nunca ouviram falar. Contudo, a maioria dos entrevistados afirmou que esse tipo de turismo interessaria a Laranjeiras, sendo que 56,7\% acham que interessaria muito e $36,6 \%$ interessaria medianamente. Apesar do interesse, 56,7\% acreditam que a cidade não está nada "preparada (infraestrutura, organização e profissionais capacitados) para receber espeleoturistas" e 33,3\% afirmam que está pouco preparada para esse tipo de turismo. No total, $70 \%$ dos entrevistados responderam que esse tipo de turismo tornaria a cidade muito mais conhecida.

Quando questionados se "esse tipo de turismo contribuiria com a economia da cidade", a maioria afirmou que sim, sendo $66,7 \%$ que contribuiria muito e $26,7 \%$ que contribuiria medianamente com a economia da cidade. Sobre os "benefícios à população que esse turismo poderia trazer", dentre os entrevistados, a maioria afirmou que sim, sendo $76,6 \%$ que contribuiria muito e $16,7 \%$ que contribuiria medianamente com a economia da cidade.

\subsection{Ações para tornar o espeleoturismo sustentável}

Para aproveitamento do potencial das cavernas para a atividade turística, por se tratar de um ambiente frágil, sua realização deve ser de forma criteriosa, principalmente porque o uso antrópico decorrente dessa atividade, na maior parte das vezes, gera impactos negativos, como afirma Lobo et al. (2010) [9]. Vários são os impactos negativos gerados pelo turismo irregular, como: falta de planejamento da atividade, uso do recurso natural além da sua capacidade e degradação das 
cavernas, caracterizada pela quebra de formações, inscrições nas paredes das cavernas, poluição por lixo e pisoteio de ornamentações do solo e ainda, a expulsão ou morte de morcegos [34].

Dessa forma, para que as visitações sejam possíveis, é imprescindível que se faça um planejamento prévio, realização de estudo para determinar a capacidade de suporte em todas as cavernas consideradas atrativo turístico, bem como, delimitar a área para visitação, promover atividades de Educação Ambiental a fim de promover a conscientização de todos os envolvidos e, elaboração de planos de manejo espeleológicos, medidas que visam garantir o uso sustentável das cavernas. O planejamento é fundamental para o desenvolvimento de um turismo equilibrado e, de acordo com Ruschmann e Widmer (2000) [43], consiste em um conjunto de atividades que envolve a intenção de estabelecer condições favoráveis para alcançar objetivos propostos.

Conforme relacionado por Carvalho (2012) [44], as etapas do planejamento são: Inventariação Turística - processo de levantamento, identificação e registro dos atrativos turísticos, dos serviços e equipamentos turísticos e da infraestrutura de apoio ao turismo [45]; Diagnóstico - compreende a análise e avaliação da situação histórica e atual do objeto que vai ser planejado; Análise de Mercado - baseia o planejamento turístico e permite conhecer a imagem do produto perante o consumidor e as tendências de demanda, tanto real ou atual, como potencial ou futura; e Prognóstico - consiste na construção de possíveis cenários futuros; é a projeção da situação atual para o futuro.

Para determinar a capacidade de suporte, que é uma ferramenta de planejamento que permite indicar a intensidade máxima de visitação permitida em um intervalo de tempo, sugere-se o método de coeficiente de rotatividade, uma forma simplificada e a mais utilizada no Brasil de controle de visitação, baseado no tempo disponível para a realização da atividade, no tempo utilizado para cumprir o roteiro e a distância percorrida [46].

A delimitação da área para visitação acontece com o estabelecimento de divisão do seu interior, definindo zonas específicas, onde deverão ser identificadas as categorias de uso para cada uma dessas zonas. Esse recurso é aplicado para alcançar os objetivos do manejo, facilitando o gerenciamento e orientação às intervenções e formas de uso de cada área delimitada ou evitando atividades indesejáveis pela inexistência de zonas apropriadas [47]. Por sua vez, o Plano de Manejo Espeleológico é um documento técnico, fundamentado nos objetivos da área, estabelecendo o zoneamento e as normas que devem presidir o uso das cavernas e o manejo dos recursos naturais, inclusive a implantação das estruturas físicas necessárias à gestão da cavidade natural subterrânea [48].

Neste processo para desenvolver o espeleoturismo em Laranjeiras de forma sustentável, a educação ambiental se torna ferramenta fundamental para uma sustentabilidade equitativa, sendo esse um processo de aprendizagem permanente. O qual é baseado no respeito a todas as formas de vida, afirmando valores e ações que contribuem para a transformação humana e social e para a preservação ecológica [49].

\section{CONCLUSÃO}

O turismo tem se apresentado como uma atividade com grande potencial econômico e capacidade de geração de emprego e renda nas localidades onde é desenvolvido e, das modalidades turísticas, o espeleoturismo tem sido visto como uma alternativa viável na utilização dos recursos naturais.

Em Sergipe, o município de Laranjeiras se destaca para o desenvolvimento do espeleoturismo por estar localizado a $18 \mathrm{~km}$ de Aracaju, possuir o maior número de cavernas conhecidas e registradas, além de haver ocorrência de visitação a esses ambientes, embora nenhuma das cavernas possua plano de manejo.

De acordo com a matriz de correlação e análise final integrada dos valores obtidos das cavidades naturais subterrâneas investigadas, verificou-se que nenhuma das cavernas pesquisadas possui potencial absoluto, intenso ou alto para espeleoturismo. Contudo, a Gruta da Matriana, a Gruta Raposinha e a Gruta da Pedra Furada, localizadas no Povoado Machado, obtiveram o maior percentual, correspondendo a $50 \%$ de potencial, classificando-as como de média potencialidade, sendo essas indicadas para visitação turística. 
A Gruta Raposinha está localizada em propriedade privada e possui pequenas dimensões, mas seria exemplo de uma caverna com degradação irreversível, e seu formato mais fechado poderia ser um contraponto à caverna maior e mais aberta, que é a Gruta da Pedra Furada, também indicada para visitação turística, possui lendas e histórias associadas, sendo a caverna mais conhecida do Estado de Sergipe e, a Gruta da Matriana, com importância histórica e está constituída por três paredões que se organizam como ângulos de um triângulo com o centro aberto, sem teto, apresentando vegetação secundária e está ilhada por canavial.

Diante do resultado das entrevistas, a maioria conhece apenas a Pedra Furada e gostam pouco das cavernas que conhecem, entretanto, afirmaram ter interesse em conhecê-las melhor e que outras pessoas também gostariam de ter essa experiência. Os entrevistados afirmaram também que a população e o poder público pouco ou nada valorizam as cavernas da região.

As entrevistas apontaram ainda que, apesar de haver visitação às cavernas de Laranjeiras, pouco se ouve falar sobre o espeleoturismo, mas, a maioria afirma que esse tipo de turismo interessaria a Laranjeiras, embora reconheça que a cidade não esteja preparada para receber espeleoturistas. Reconheceram também que esse tipo de turismo contribuiria com a economia da cidade e que poderia trazer benefícios à população.

Assim, os resultados da análise das cavidades naturais subterrâneas evidenciam que, apesar de não possuírem potencial absoluto, intenso ou alto para espeleoturismo, o município de Laranjeiras detém três cavernas localizadas no Povoado Machado, indicadas para visitação turística, classificadas como de média potencialidade, sendo necessário associar a outras belezas naturais e/ou históricas, para incrementar a potencialidade turística. Entretanto, é imprescindível que esse turismo aconteça de forma organizada, contando com profissionais que realizem uma condução responsável, além da efetivação de atividades de sensibilização e educação ambiental junto à comunidade local, para que essa detenha maior conhecimento sobre as cavernas de Laranjeiras, de modo que contribua para sua conservação e uso sustentável.

\section{REFERÊNCIAS BIBLIOGRÁFICAS}

1. Lobo HAS. Método para avaliação do potencial espeleoturístico do Parque Nacional da Serra de Bodoquena, MS. Caderno Virtual de Turismo. 2007;7(3):99-110.

2. Barbosa EP, Travassos LEP. Caves, stories, history and popular traditions in the semi-desert (sertão) of Bahia, northeastern Brazil. Acta Carsologica. 2008;37(2-3):331-338.

3. Fraga I. As casas dos espíritos. Ciência Hoje, Rio de Janeiro, 04 jul. 2011. Disponível em: <http://cienciahoje.uol.com.br/revista-ch/2011/282/as-casas-dos-espiritos>. Acesso em: 01 ago. 2011.

4. Diário do Nordeste. Gruta franciscana. SBE Antropoespeleologia. 200915 jan;2(16).

5. Agência Ecclesia. Gruta da Anunciação em Nazaré. SBE Antropoespeleologia. 200915 jan;2(16). AFP. Colombiano criava cinco filhos em caverna. SBE Antropoespeleologia. 201015 ago;3(35).

6. Lino CF. Cavernas: o fascinante Brasil subterrâneo. São Paulo: Gaia; 2001.

7. Karnopp PKF et al. Espeleologia: um instrumento de difusão da educação ambiental em atividades ecoturísticas. Physis, 2007. Disponível em: <http://www.physis.org.br/ecouc/Artigos/Artigo24.pdf >. Acesso em: 30 out. 2012.

8. Lobo HAS et al. Espeleoturismo: oferta e demanda em crescente expansão e consolidação no Brasil. In: Brasil. Ministério do Turismo. Segmentação do turismo: experiências, tendências e inovações. Brasília, DF; 2010.

9. Travassos LEP, Batella WB. Espacializando a importância da Caverna de Postojna (Postojnska Jama) para o turismo ao longo da história eslovena. Campinas, SeTur/SBE. Turismo e Paisagens Cársticas. 2010;3(1):11-19.

10. Branner JC. The Cretaceous and Terciary Geology of the Sergipe - Alagoas basin of Brazil. Transactions of the American Philosophical Society - New series. 1888;16(3):369-434.

11. Ferreira JP. Enciclopédia dos municípios brasileiros. Rio de Janeiro, v. 19; 1959.

12. Prous A. Arqueologia Brasileira. Brasília: Editora da UnB; 1992.

13. Santos DB, Oliveira DA, Menezes HJS. Registros preliminares de cavidades naturais em Sergipe. In: $2^{\circ}$ Workshop Arqueológico de Xingó, Canindé do São Francisco, SE; 2002. p. 117-122.

14. Carvalho MSS, Gallo V. The presence of Ptychodus (Chondrichthyes, Hybodontoidea) in the Cotinguiba formation, upper Cretaceous of the Sergipe - Alagoas basin, northeasthern Brazil. In: $6^{\circ}$ Simpósio sobre o Cretáceo do Brasil, $2^{\circ}$ Simposio sobre el Cretácico de América del Sur; São Pedro, SP; 2002. p. 307309. 
15. Lôbo D et al. Ocorrência de Geochelone (Reptilia - Testudinidae) no Abismo de Simão Dias, Sergipe, Brasil. In: $27^{\circ}$ Congresso Brasileiro de Espeleologia, Januaria, MG. Resumos Expandidos..., 2003. p. 17.

16. Dantas MAT. Primeiro registro de fósseis de mamíferos pleistocênicos em caverna de Sergipe, Brasil. Rev. bras. paleontol. maio/ago. 2009;12(2):161-164.

17. Leão TC, Lôbo D, Silva EJ. Conservação, geologia e levantamento da fauna de invertebrados associados ao guano da caverna do Urubu (SE-10), Riachuelo, Sergipe. In: $27^{\circ}$ Congresso Brasileiro de Espeleologia. Januaria, MG; 2003. p. 1-9.

18. Donato $\mathrm{CR}$ et al. Análise preliminar da classificação ecológica dos representantes faunísticos da caverna de Pedra Branca, Laranjeiras, Sergipe. In: $7^{\circ}$ Congresso Internacional Sobre Manejo da Fauna Silvestre na Amazônia e América Latina, Ilhéus, BA; 2006a. p. 300.

19. Donato CR et al. Análise preliminar dos morcegos (Chiroptera, Phyllostomidae) da caverna de Pedra Branca, Laranjeiras, Sergipe. In: Congresso Internacional Sobre Manejo da Fauna Silvestre na Amazônia e América Latina, 7. Ilhéus, BA; 2006b. p. 301.

20. Donato CR et al. Ocorrência de Cardisoma guanhumi (Decapoda, Gecarcinidae) na caverna de Pedra Branca, Laranjeiras, Sergipe. In: Congresso Internacional Sobre Manejo da Fauna Silvestre na Amazônia e América Latina, 7. Ilhéus, BA; 2006c. p. 302.

21. Dantas MAT et al. Inventário Espeleológico de Sergipe: As cavernas de Laranjeiras In: XXX Congresso Brasileiro de Espeleologia, 2009, Montes Claros, MG; 2009. p. 43-50.

22. Santana MEV et al. Levantamento da fauna de invertebrados cavernícolas na Toca da Raposa, Simão Dias, Sergipe, Brasil - resultados preliminares. In: XXX Congresso Brasileiro de Espeleologia, 2009, Montes Claros, MG. Anais... 2009. p.221-225.

23. Donato CR, Dantas MAT. Utilização de CD-ROM como instrumento de aprendizagem significativa sobre a Bioespeleologia sergipana In: XXX Congresso Brasileiro de Espeleologia, 2009, Montes Claros, MG; 2009. p. 51-56.

24. Ferreira AS et al. Levantamento da herpetofauna da gruta Raposinha, Laranjeiras, Sergipe - dados preliminares In: XXX Congresso Brasileiro de Espeleologia, 2009, Montes Claros, MG; 2009a. p. 63-68.

25. Ferreira AS, Dantas MAT, Donato CR. Ocorrência de Leptodactylus vastus Lutz, 1930 (Amphibia, Anura, Leptodactylidae) na Caverna Toca da Raposa, Simão Dias, Sergipe In: XXX Congresso Brasileiro de Espeleologia, 2009, Montes Claros, MG; 2009b. p. 57-62.

26. Donato CR, Macedo HS. Localização geográfica de cavernas: a importância de saber manipular instrumentos e analisar os dados. In: Rasteiro MA, Morato L. (orgs.) Congresso Brasileiro de Espeleologia, 32, 2013. Barreiras.Campinas: SBE; 2013. p. 267-272. Disponível em: <http://www.cavernas.org.br/anais32cbe/32cbe_267-272.pdf>. Acesso em: 15 jan. 2016.

27. Donato CR, Ribeiro AS, Sousa-Souto L. Análise ambiental e avaliação da relevância das cavernas do Município de Laranjeiras, Sergipe. Espeleo-Tema (São Paulo). 2012; 23: 59-69. Disponível em: <http://www.cavernas.org.br/espeleo-tema/espeleo-tema_v23_n2_059-069.pdf>. Acesso em: 15 out. 2013.

28. Donato CR, Ribeiro AS, Souto LS. A conservation status index, as an auxiliary tool for the management of cave environments. International Journal of Speleology. 2014;43(3):315-322. doi:10.5038/1827806X.43.3.8

29. Donato CR, Ribeiro AS. Caracterização dos impactos ambientais de cavernas do município de Laranjeiras, Sergipe. Caminhos de Geografia. $2011 \mathrm{dez}$;12(40):243-255.

30. Donato CR, Souza AVM. Sentidos em movimento: práticas discursivas em conservação espeleológica. In: Rasteiro MA, Sallun Filho W (orgs.) $33^{\circ}$ Congresso Brasileiro de Espeleologia, 2015. Eldorado. Campinas: SBE, 2015. p. 241-250. Disponível em: <http://www.cavernas.org.br/anais33cbe/33cbe_241250.pdf>. Acesso em: 19 jul. 2015.

31. Donato CR. Análise de impacto sobre as cavernas e seu entorno no Município de Laranjeiras, Sergipe [dissertação]. São Cristóvão: Universidade Federal de Sergipe; 2011. 198 p.

32. Donato CR. Dinâmica ambiental espeleológica: memória, conservação e educação [tese]. São Cristóvão: Universidade Federal de Sergipe; 2016. 252 p.

33. Carvalho ES, Muricy JS. Cavernas de Laranjeiras. Centro da Terra Grupo Espeleológico de Sergipe (Org.). Aracaju: Página 5 Serviços Editoriais; 2015.

34. Correia CO (coord.). Sergipe Atlas Digital Sobre Recursos Hídricos. Versão 1.1. Departamento de Administração e Controle de Recursos Hídricos, Coordenadoria de Informações sobre Recursos Hídricos; 2004. 1 CD-ROM.

35. Sergipe. Diagnóstico do Município de Laranjeiras. Luiz Fernando Costa Bomfim, Ivanaldo Vieira Gomes da Costa e Sara Maria Pinotti Benvenuti. Aracaju: CPRM; 2002. 
36. IBGE. Censo Demográfico 2010. Rio de Janeiro: IBGE, 2010. Disponível em: <http://www.censo2010.ibge.gov.br/dados_divulgados/index.php?uf=28>. Acesso em Acesso em 04 nov. 2010.

37. IPHAN. Instituto do Patrimônio Histórico e Artístico Nacional. Tombamento definitivo do Conjunto Arquitetônico, Urbanístico e Paisagístico da cidade de Laranjeiras, Segipe. Aracaju: IPHAHN; 2009.

38. Sergipe. Secretaria de Estado da Agricultura e do Desenvolvimento Agrário. Informações Básicas Municipais: município de Laranjeiras. Aracaju; 2008.

39. Prefeitura Municipal de Laranjeiras (PML), Perfil do Projeto Laranjeiras/SE - Programa Monumenta. dez. 2003.

40. Lobo HAS et al. Reflexões e propostas para as políticas públicas de espeleoturismo no Brasil. Revista Global Tourism. 2007:1-17.

41. Souza-Silva M, Ferreira RL. Caracterização ecológica de algumas cavernas do Parque Nacional de Ubajara (Ceará) com considerações sobre o turismo nestas cavidades. Revista de Biologia e Ciências da Terra. 2009 jan-jun;9(1):59-71.

42. Ruschmann DVM, Widmer GM. Planejamento turístico. In: Ansarah MGR (Org.). Turismo: como aprender, como ensinar. São Paulo, SP: Editora Senac São Paulo; 2000.

43. Carvalho ES. Análise do potencial turístico do patrimônio espeleológico no município de Laranjeiras/SE. [Monografia]. Aracaju: Instituto Federal de Educação, Ciência e Tecnologia de Sergipe; 2012.70 p.

44. Brasil. Ministério do Turismo. Módulo Operacional 4: Elaboração do plano estratégico de desenvolvimento do turismo regional. Ministério do Turismo: Brasília; 2007.

45. Lobo HAS et al. Capacidade de carga turística em cavernas: estado-da-arte e novas perspectivas. SBE Espeleo-Tema. 2009;20(1/2):37-47.

46. Marra RJC. Espeleoturismo: planejamento e manejo de cavernas. WD Ambiental: Brasília; 2001.

47. CONAMA - Conselho Nacional do Meio Ambiente. Resolução no 347, de 10 de setembro de 2004. Dispõe sobre a proteção do patrimônio espeleológico. Diário Oficial da União, Brasília, DF, nº 176, 13 set. 2004. Seção 1, p. 54-55. Disponível em: <http://www.mma.gov.br/port/conama/res/res04/res34704.xml>. Acesso em: 10 nov. 2015.

48. MMA - Ministério do Meio Ambiente. Tratado de Educação Ambiental para Sociedades Sustentáveis e Responsabilidade Global. [s/d]. $\quad$ Disponível em: <http://www.mma.gov.br/port/sdi/ea/documentos/docs/tratea.htm>. Acesso em: 11 nov. 2015. 